\title{
MộT Số YẾU Tố ẢNH HƯởNG ĐẾN CHỨC NĂNG TIM THAI Ở SẢN PHU TIỀN SẢN GIÂT TAII KHOA PHỤ SẢN VÀ VIỆN TIM MẠCH BỆNH VIỆN BẠCH MAI
}

\author{
Nguyễn Phương Thảo ${ }^{1}$, Phạm Thị Hồng Thi ${ }^{2}$, \\ Phạm Bá Nha ${ }^{3}$, Nguyễn Thị Duyên ${ }^{1}$
}

\section{TÓM TẮT}

Mục tiêu: Nghiên cứu một số yếu tố ảnh hưởng đến chức năng tim thai ở sản phụ tiên sản giật. Đối tượng và phương pháp: Nhóm bệnh: 20 sản phụ tiên sản giật $\geq 18$ tuổi có thai từ 28 tuần trở lên, thai tự nhiên, không mắc các bệnh cấp và mạn tính. Nhóm chứng: 20 sản phụ khỏe mạnh có tuổi mẹ và tuổi thai tương đương, thai tự nhiên, không mắc các bệnh cấp và mạn tính; Cả hai nhóm đều thực hiện xét nghiệm sàng loc cơ bản trước sinh bình thường, đến khám và điều trị tại Khoa Phụ Sản và Viện Tim mạch Bênh viện Bach Mai trong thời gian từ 08/2019 đến 8/2020. Thực hiện siêu âm tim thai và thu thập thông tin từ hồ sơ bênh án tai bênh viện theo mấu bênh án nghiên cứu thống nhất. Kểt quả và kết luận: Những chỉ số lâm sàng có ảnh hưởng đến chức năng của tim phải của thai nhi khi biểu hiện bằng chỉ số Tei thất phải gồm: BMI trước mang thai $(r=0,336, p<0,05)$, huyết áp tâm thu $(r=0,333, p<0,05)$ và huyết áp tâm trương $(r=0,381, p<0,05)$. Bên cạnh đó, huyết áp tâm thu $(\mathrm{r}=0,364, \mathrm{p}<0,05)$, huyểt áp tâm trương $(p=0,337, p<0,05)$ và LDL-C $(r=0,471, p<0,05)$ là những chỉ số có ảnh hưởng đến chức năng tim trái của thai nhi thông qua chỉ số Tei thất trái. Khi siêu âm Doppler động mach tử cung, có mối tương quan đồng biến giữa chỉ số RI với: chỉ số tim ngực $(r=0,726$, $p<0,001)$, đường kính tâm thu thất phải $(r=0,730$, $\mathrm{p}<0,05$ ), các chỉ số hình thái tim (mức tương quan tương đối chặt chẽ, $\mathrm{p}<0,05)$, chî số Tei thất phải $(r=0,374, p<0,05)$. Chiêu dày của các thành tim thai và chỉ số VTI của tim thai nhi qua ĐMC, ĐMP ở nhóm sản phụ có chỉ số kháng trở động mạch tử cung RI $>0,55$ với nhóm lớn hơn một cách có ý nghĩa so với nhóm sản phụ có chỉ số $R I \leq 0,55$ với $p<0,05$.

Tư khóa: tiền sản giật, chức năng tim thai

\section{SUMMARY \\ TO INVESTIGATE FACTORS THAT EFFECT FETAL CARDIAC FUNCTION IN PRE- ECLAMPSIA PREGNANT WOMEN AT DEPARTMENT OF OBSTETRICS AND GYNECOLOGY AND VIETNAM NATIONAL HEART INSTITUTE OF BACH MAI HOSPITAL}

\author{
${ }^{1}$ Bênh viện Vinmec Hạ Long \\ 2Viện Tim mach Việt Nam \\ ${ }^{3}$ Trường Đại hoc Y Hà Nôi \\ Chịu trách nhiệm chính: Nguyễn Phương Thảo \\ Email: bacsiphuongthaonguyen@gmail.com \\ Ngày nhận bài: 20.10.2020 \\ Ngày phản biên khoa học: 25.11.2020 \\ Ngày duyệt bài: 10.12 .2020
}

Objectives: To investigate factors that effect fetal cardiac function in pre-eclampsia pregnant women. Objects and methods: Fortypregnant women, who have some characteristics:greater than or equal to 18 year olds, have 28th week of pregnancy and above, not suffer from acute and chronic diseases, basic prenatal screening tests are nomal, come for medical examination and treatment at Department of Obstetrics and Gynecology and Vietnam National Heart Institute of Bach Mai Hospital from August 2019 to August 2020. Results and Conclusions: There are some clinical factors affect the fuction of the fetal right heart expressed by Tei index of the right ventricular: pre-pregnant BMI $(r=0,336, p<0,05)$, systolic blood pressure $(r=0.333, p<0.05)$ and diastolic blood pressure $(r=0.381, p<0.05)$. In addition, systolic blood pressure $(r=0.364, p<0.05)$, diastolic blood pressure $(p=0.337, p<0.05)$ and LDL-C $(r=0.471$, $\mathrm{p}<0.05)$ are factors that affect the fetal left cardiac function through the left ventricular Tei index. For Doppler untrasound of uterine artery, there are positivecorelation between Resistive Index (RI) and some indicators, such as: cardiothoracic ratio $(r=0,726, p<0,001)$, systole right ventricular diameter $(r=0,730, \quad p<0,05)$, cardiac morphology index (relatively close correlation, $\mathrm{p}<0,05$ ) and Tei index of the left ventricular $(r=0,374, p<0,05)$. The thickness of the fetal cardiac wall and fetal cardiac VTI index measured through the aorta and pulmonary artery in the group with resistive index of uterine arterial RI> 0.55 are significantly greater than the group with RI $\leq 0.55$ with $\mathrm{p}<0.05$.

Keywords: pre-eclampsia, fetal cardiac function.

\section{I. ĐĂT VẤN ĐỀ}

Tiền sản giật (TSG) là bệnh lý tim mạch - sản khoa phức tạp gây ra tử vong và biển chứng nặng nề cho mẹ, thai nhi và sơ sinh. TSG gây những biến chứng nặng cho mẹ: sản giật, rau bong non, rối loạn đông máu, suy gan, suy thận, chảy máu, phù phổi cấp và biến chứng đối với con:thai chậm phát triển, suy thai, sinh non, suy hô hấp sơ sinh, tăng tỉ lệ bệnh và di chứng cho sự phát triển của trẻ sau này ${ }^{1,2,3}$. Siêu âm tim thai đánh giá rối loạn chức năng tim của thai nhi là công cụ chẩn đoán trước sinh với độ nhạy và độ đặc hiệu cao $87,3 \%$ và $99,1 \%$ giúp cải thiện tiên lượng thông qua việc kiểm soát các yếu tố tác nguy cơ, nâng cao kết quả điều trị̣ ${ }^{4,5}$.

II. ĐỐl TƯợNG VÀ PHƯƠNG PHÁP NGHIÊN CỨU

1. Đối tượng và địa điểm nghiên cứu: 
Nhóm bệnh20 sản phụ tiền sản giật $\geq 18$ tuổi có thai từ 28 tuần trở lên, thai tự nhiên, không mắc các bệnh cấp và mạn tính.

Nhóm chứng: 20 sản phụ khỏe mạnh có tuổi me và tuổi thai tương đương, thai tự nhiên, không mắc các bệnh cấp và mạn tính; Cả hai nhóm đều thực hiện xét nghiệm sàng lọc cơ bản trước sinh bình thường, đến khám và điều trị tại Khoa Phụ Sản và Viện Tim mạch Bệnh viện Bạch Mai trong thời gian từ 08/2019 đến 8/2020.

2. Phương pháp nghiên cứu: Mô tả cắt ngang có nhóm đối chứng

3. Phương pháp thu thập thông tin: III. KẾT QUẢ NGHIÊN CứU VÀ BÀN LUẬN

\section{1. Đặc điểm của nhóm nghiên cứu}

Bảng 1. Đăc điểm lâm sàng và cân lâm sàng của nhóm nghiên cứu

\begin{tabular}{|c|c|c|c|}
\hline \multirow[b]{2}{*}{$\begin{array}{c}\text { Các thông số } \\
\text { nghiên cứu cưa mẹ }\end{array}$} & \multicolumn{2}{|c|}{ Trung bình \pm SD } & \multirow[b]{2}{*}{$\mathbf{p}$} \\
\hline & $\begin{array}{c}\text { Nhóm sản phụ } \\
\text { tiền sản giật }(n=20)\end{array}$ & $\begin{array}{c}\text { Nhóm chứng } \\
(n=20)\end{array}$ & \\
\hline \multicolumn{4}{|c|}{ Đăc điếm lâm sàng } \\
\hline Tuối (năm) & $30,55 \pm 4,48$ & $27,80 \pm 5,18$ & 0,0812 \\
\hline BMI trước mang thai $\left(\mathrm{kg} / \mathrm{cm}^{2}\right)$ & $23,14 \pm 0,97$ & $20,11 \pm 2,01$ & $<0,001$ \\
\hline Huyết áp tâm thu (mmHg) & $170,75 \pm 11,95$ & $114,75 \pm 9,80$ & $<0,001$ \\
\hline Huyết áp tâm trương $(\mathrm{mmHg})$ & $95 \pm 4,87$ & $60,75 \pm 8,63$ & $<0,001$ \\
\hline Số lần mang thai (lần) & $2,4 \pm 0,99$ & $1,35 \pm 0,49$ & $<0,001$ \\
\hline Con so, n (\%) & $4(20)$ & $13(65)$ & 0,005 \\
\hline Con rạ, n (\%) & $16(80)$ & $7(35 \%)$ & 0,005 \\
\hline \multicolumn{4}{|c|}{ Đặc điếm cận lầm sàng } \\
\hline Hồng câu (T/L) & $4,15 \pm 0,43$ & $3,90 \pm 0,35$ & 0,051 \\
\hline $\mathrm{Hb}(\mathrm{g} / \mathrm{L})$ & $106,50 \pm 12,64$ & $121 \pm 9,99$ & $<0,001$ \\
\hline Bạch cầu ( G/L) & $10,31 \pm 1,67$ & $8,49 \pm 1,20$ & $<0,001$ \\
\hline Tiếu cầu (G/L) & $210,90 \pm 37,40$ & $288,45 \pm 95,35$ & 0,002 \\
\hline Triglyceride $(\mathrm{mmol} / \mathrm{L})$ & $3,39 \pm 0,26$ & $7,84 \pm 23,14$ & 0,395 \\
\hline Cholesterol (mmol/L) & $6,00 \pm 0,45$ & $5,57 \pm 1,34$ & 0,191 \\
\hline $\mathrm{LDL} \mathrm{C}(\mathrm{mmol} / \mathrm{L})$ & $3,70 \pm 0,57$ & $3,17 \pm 0,15$ & $<0,001$ \\
\hline GOT (U/L) & $44,10 \pm 17,52$ & $27,25 \pm 5,88$ & $<0,001$ \\
\hline GPT (U/L) & $39,75 \pm 20,33$ & $24,30 \pm 5,77$ & $<0,001$ \\
\hline Urea (mmol/L) & $7,37 \pm 2,42$ & $6,26 \pm 0,01$ & 0,066 \\
\hline Creatinine $(\mu \mathrm{mol} / \mathrm{L})$ & $86,10 \pm 15,85$ & $82,19 \pm 0,22$ & 0,077 \\
\hline Protein toàn phần $(\mathrm{g} / \mathrm{L})$ & $55,50 \pm 4,47$ & $63,05 \pm 2,58$ & $<0,001$ \\
\hline Albumin $(\mathrm{g} / \mathrm{L})$ & $28,15 \pm 3,35$ & $34,18 \pm 2,35$ & $<0,001$ \\
\hline Chỉ số RI & $0,66 \pm 0,05$ & $0,52 \pm 0,06$ & $<0,001$ \\
\hline
\end{tabular}

Độ tuổi của sản phụ trong nghiên cứu của chúng tôi từ $25-40$, trung bình của nhóm bệnh là $30,5 \pm 4,48$ và nhóm chứng là $27,80 \pm 5,18$, tương đương với kết quả trong nghiên cứu của Phạm Thị Mai Anh' ${ }^{6}$ độ tuổi của sản phụ nhóm $25-34$ tuổi chiếm tỉ lể $55 \%$. Không có sự khác biệt về tuổi ở nhóm sản phụ TSG so với nhóm sản phụ bình thường $(p>0,05)$. BMI trung bình của nhóm bệnh là $23,14 \pm 0,97$, lớn hơn nhiều so với nhóm khỏe mạnh là $20,11 \pm 2,01$
Thực hiệnsiêu âm tim thai và thu thập thông tin từ hồ sơ bệnh án tại bệnh viện theo mẫu bệnh án nghiên cứu thống nhất.

4. Quản lý và xử lý số liệu bằng phần mềm SPSS 20.0, kiểm định tính chuẩn của số liệu (Skewness - Kurtosis), tỷ lệ phần trăm, phi tham số, T-test, khi bình phương $\left(X^{2}\right)$, Fisher'exact test, hệ số tương quan ( $r$ ), tỉ suất chênh (OR) với $p<0,05$.

5. Đạo đức nghiên cứu: Nghiên cứu được thực hiện đúng theo quy định về đạo đức trong nghiên cứu y học. Tất cả các thông tin thu thập được bảo mật và chỉ phục vụ cho nghiên cứu. $(p<0,001)$. HATT và HATTr của nhóm sản phụ TSG cao hơn so với nhómchứng.

Sản phụ TSG có biểu hiện thiếu máu nhẹ ( $\mathrm{Hb}$ $106,50 \pm 12,64, p<0.05)$. Số lượng bạch cầu trung bình ở nhóm bệnh là 10,31 $\pm 1,67$ cao hơn nhiều so với ở sản phụ khỏe mạnh là $8,49 \pm$ 1,20 , trong khi đó tiểu cầu ở nhóm bệnh là 210 , $90 \pm 1,67$ thấp hơn so với nhóm khỏe mạnh là $288 \pm 95,35$. Chỉ số men gan (GOT và GPT) của nhóm TSG $(44,10 \pm 17,52$ và $39,75 \pm 20,33)$ 
cao hơn nhiều so với nhóm khỏe manh $(27,25 \pm$ $5,88$ và $24,30 \pm 5,77)(p<0,05)$. Các chỉ số này đều phản ánh hội chứng HELLP xuất hiện ở sản phụ TSG. Đây là biến chứng rất nặng, diễn biến rất nhanh và có thể đe dọa tính mạng mẹ và bé.

\section{Bảng 2: Các đặc điểm về thai và và hình thái, chức năng tim thai ở nhóm nghiên cứu}

\begin{tabular}{|c|c|c|c|}
\hline \multirow[b]{2}{*}{$\begin{array}{c}\text { Các thông sốnghiên cứu } \\
\text { của thai nhi }\end{array}$} & \multicolumn{2}{|c|}{ Trung bình \pm SD } & \multirow[b]{2}{*}{$\mathbf{p}$} \\
\hline & $\begin{array}{l}\text { Nhóm sản phụ } \\
\text { tiên sản giâtt }(n=20)\end{array}$ & $\begin{array}{l}\text { Nhóm chứng } \\
(n=20)\end{array}$ & \\
\hline Cân nặng thai nhi (gram) & $776,45 \pm 37,45$ & $1002,55 \pm 204,67$ & $<0,001$ \\
\hline Tân số tim thai (chu kỳ/phút) & $145,70 \pm 6,39$ & $148,45 \pm 6,57$ & 0,187 \\
\hline Chỉ số tim ngực & $0,35 \pm 0,02$ & $0,29 \pm 0,03$ & $<0,001$ \\
\hline Bề dày thất phải tâm trương $(\mathrm{mm})$ & $3,01 \pm 0,29$ & $2,36 \pm 0,27$ & $<0,001$ \\
\hline Bề dày thất phải tâm thu (mm) & $3,88 \pm 0,55$ & $3,33 \pm 0,28$ & $<0,001$ \\
\hline Bề dày thất trái tâm trương $(\mathrm{mm})$ & $2,92 \pm 0,29$ & $2,18 \pm 0,22$ & $<0,001$ \\
\hline Bề dày thất trái tâm thu (mm) & $3,73 \pm 0,58$ & $3,17 \pm 0,25$ & $<0,001$ \\
\hline Bề dày VTL tâm trương (mm) & $3,17 \pm 0,29$ & $2,60 \pm 0,23$ & $<0,001$ \\
\hline Bề dày VLT tâm thu (mm) & $4,09 \pm 0,38$ & $3,61 \pm 0,32$ & $<0,001$ \\
\hline VTI ĐMC $(\mathrm{cm} / \mathrm{s})$ & $11,43 \pm 1,05$ & $7,65 \pm 0,30$ & $<0,001$ \\
\hline VTI ĐMP $(\mathrm{cm} / \mathrm{s})$ & $9,51 \pm 0,60$ & $6,69 \pm 0,19$ & $<0,001$ \\
\hline Phât suất co rút cơ (FS) & $32,84 \pm 2,09$ & $35,02 \pm 5,31$ & 0,101 \\
\hline Chỉ số Tei thất trái & $0,39 \pm 0,02$ & $0,36 \pm 0,05$ & 0,022 \\
\hline Chỉ số Tei thất phải & $0,42 \pm 0,02$ & $0,40 \pm 0,04$ & 0,025 \\
\hline
\end{tabular}

Chỉ số tim ngực và các chiều dày các thành tim của thai nhi ở nhóm sản phụ TSG lớn hơn so với nhóm chứng $(\mathrm{p}<0,001)$. Nghiên cứu chưa tìm thây các rối loạn chức năng tâm trương, tuy nhiên chức năng tim toàn bộ (biểu hiện qua chỉ số Tei) ở tim thai ở sản phụ TSG giảm hơn so với nhóm chứng $(p<0,005)$. Hơn nữa, theo Narin và cộng sự 12 , rối loạn chức năng tim và tổn thương cơ tim đã được tìm thấy ở trẻ sơ sinh của các bệnh nhẩn TSG.

2. Một số chỉ số lâm sàng có ảnh hưởng đến chức năng của tim thai, biểu hiện qua chỉ số Tei thất phải và Tei thất trái.

Bảng 3. Ánh hưởng của một số chỉ số lâm sàng lên chức năng tim của thai nhi

\begin{tabular}{|c|c|c|c|c|}
\hline \multirow{2}{*}{$\begin{array}{c}\text { Các yếu tố lâm sàng } \\
\text { và cận lâm sàng }\end{array}$} & \multicolumn{2}{|c|}{$\begin{array}{c}\text { Tương quan với } \\
\text { chí số Tei thất phải }\end{array}$} & \multicolumn{2}{|c|}{$\begin{array}{c}\text { Tương quan với } \\
\text { chỉ số Tei thất trái }\end{array}$} \\
\cline { 2 - 5 } & $\mathbf{r}$ & $\mathbf{p}$ & $\mathbf{R}$ & $\mathbf{p}$ \\
\hline BMI trước mang thai & 0,336 & 0,034 & 0,035 & 0,056 \\
\hline Huyết áp tâm thu (mmHg) & 0,333 & 0,036 & 0,364 & 0,021 \\
\hline Huyết áp tâm trương $(\mathrm{mmHg})$ & 0,381 & 0,015 & 0,337 & 0,033 \\
\hline LDL-C $(\mathrm{mmol} / \mathrm{L})$ & 0,342 & 0,031 & 0,471 & 0,002 \\
\hline Tiếu cầu $(\mathrm{G} / \mathrm{L})$ & $-0,274$ & 0,087 & $-0,329$ & 0,038 \\
\hline
\end{tabular}

Những chỉ số lâm sàng có ảnh hưởng đến chức năng tim phải của thai nhi khi biểu hiện bằng chỉ số Tei thất phải gồm: BMI trước mang thai $(r=0,336, p<0,05)$, huyết áp tâm thu $(r=0,333, p<0,05)$ và huyết áp tâm trương $(r=0,381, p<0,05)$.
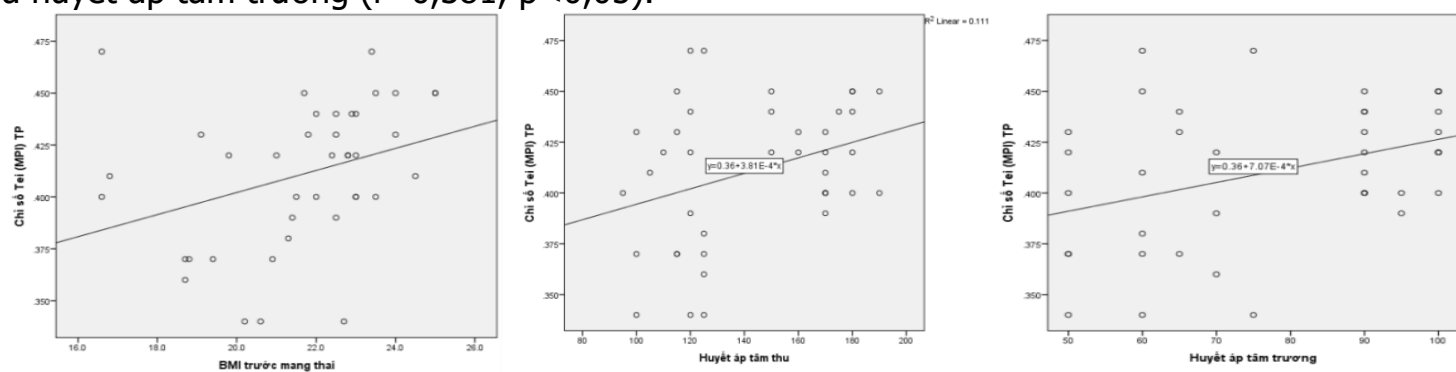

Biểu đồ 1. Ảnh hưởng của BMI trước mang thai $\left(\mathrm{kg} / \mathrm{m}^{2}\right)$, huyết áp tâm thu $(\mathrm{mmHg})$ và huyêt áp tâm trương $(\mathrm{mmHg})$ của sản phụ lên chi số Tei thất phải của tim thai

Huyết áp tâm thu $(r=0,364, p<0,05)$, huyết áp tâm trương $(p=0,337, p<0,05)$ và $L D L-C(r=0,471$, $p<0,05)$ là những chỉ số có ảnh hưởng đến chức năng tim trái của thai nhi thông qua chỉ số Tei thất trái. 

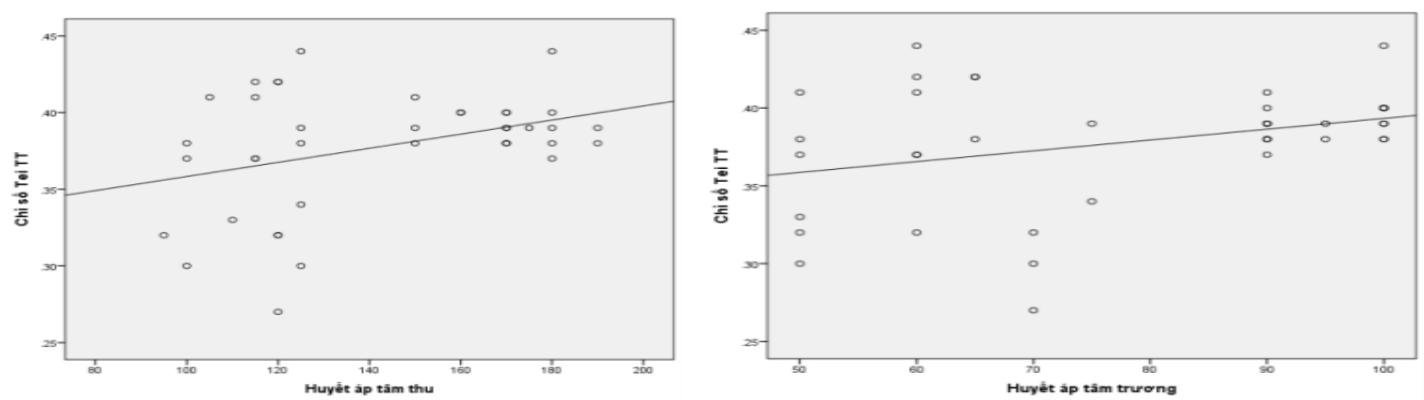

Biểu đồ 2. Ảnh hưởng của huyêt áp tâm thu ( $\mathrm{mmHg}$ ) và huyêt áp tâm trương ( $\mathrm{mmHg}$ ) của sản phụ lên chỉ số Tei thất trái của tim thai

Bảng 3: Tương quan giữa chỉ số kháng trở động mạch tứ cung (RI)với hình thái và chức năng tim thai

\begin{tabular}{|c|c|c|}
\hline & \multicolumn{2}{|c|}{$\begin{array}{l}\text { Tương quan với } \\
\text { RI }(n=40)\end{array}$} \\
\hline & $\mathbf{R}$ & \\
\hline Chỉ số tim ngực & 0,726 & $<0,001$ \\
\hline $\begin{array}{l}\text { Bề dày thất phải tâm } \\
\text { trương }(\mathrm{mm})\end{array}$ & 0,626 & 0,001 \\
\hline $\begin{array}{l}\text { Bề dày thất trái tâm trương } \\
(\mathrm{mm})\end{array}$ & 0,665 & 0,001 \\
\hline $\begin{array}{l}\text { Bề dày thất phải tâm thu } \\
(\mathrm{mm})\end{array}$ & 0,421 & 0,007 \\
\hline $\begin{array}{l}\text { Bề dày thất trái tâm thu } \\
(\mathrm{mm})\end{array}$ & 0,415 & 0,008 \\
\hline $\begin{array}{l}\text { Bề dày VTL tâm trương } \\
(\mathrm{mm})\end{array}$ & 0,555 & $<0,001$ \\
\hline Bề dày VLT tâm thu $(\mathrm{mm})$ & 0,424 & 0,006 \\
\hline Chí số Tei thất phải & 0,374 & 0,017 \\
\hline Chỉ số Tei thất trái & 0,003 & 0,353 \\
\hline VTI động mạch chủ $(\mathrm{cm} / \mathrm{s})$ & 0,743 & $<0,001$ \\
\hline VTI động mạch phối $(\mathrm{cm} / \mathrm{s})$ & 0,721 & $<0,001$ \\
\hline
\end{tabular}

Khi siêu âm Doppler động mạch tử cung, có mối tương quan đồng biến giữa chỉ số RI với: chỉ số tim ngực $(r=0,726, p<0,001)$, đường kính thất phải tầm thu $(r=0,730, p<0,05)$, các chỉ số hình thái tim (mức tương quan tương đối chă̆t chẽ, $p<0,05)$, chỉ số Tei thất phải $(r=0,374$, $\mathrm{p}<0,05)$.

Trên thế giới có nhiều nghiên cứu chỉ ra sự tương quan giữa THA, TSG và rối loạn chức năng tim thai. Ayman Fouad Ahmed Sabry và Khalid $F$ Elnaahas (2016) khi nghiên cứu về các nguyên nhân gây THA ở me với các biến chứng đối với chức năng tim thai ${ }^{\dagger}$ ở 59 sản phụ đơn thai bi THA với tuổi thai từ 22-30 tuần kết quả cho thấy rằng khi mẹ bị THA, TSG hoặc THA mạn tính, chức năng tim thai và chỉ số động mạch rốn đều có các rối loạn đáng kể. Balli (2013) khi đánh giá chức năng tim thai trên sản phụ TSG nhe cũng ghi nhận những sự thay đổi về hình thái và chức năng tim trên tim thai ${ }^{8}$. TSG làm giảm lượng oxy của thai nhi nhận qua nhau thai, hậu quả làm tim lớn và dày thành tim cũng như ĐMC thể hiện qua các chỉ số về hình thái của tim bao gồm chỉ số tim ngực, bề dày thành thất ở thai nhi của sản phụ TSG lớn hơn nhóm sản phụ khỏe mạnh

Bảng 4. Ảnh hưởng của chỉ số kháng trở động mạch tử cung với điểm cắt RI>0,55 lên hình thái và chức năng tim thai

\begin{tabular}{|c|c|c|c|}
\hline \multirow{2}{*}{$\begin{array}{l}\text { Các thông số } \\
\text { nghiên cứu của thai nhi }\end{array}$} & \multicolumn{2}{|c|}{ Trung bình \pm SD } & \multirow[b]{2}{*}{ p } \\
\hline & $R I>0,55(n=28)$ & $R I \leq 0,55(n=12)$ & \\
\hline Chỉ số tim ngực & $0,33 \pm 0,04$ & $0,29 \pm 0,02$ & 0,001 \\
\hline Bề dày thất phải tâm trương (mm) & $2,85 \pm 0,38$ & $2,3 \pm 0,30$ & $<0,001$ \\
\hline Bề dày thất phải tâm thu (mm) & $3,75 \pm 0,52$ & $3,26 \pm 0,29$ & $<0,001$ \\
\hline Bề dày thất trái tâm trương $(\mathrm{mm})$ & $2,73 \pm 0,39$ & $2,13 \pm 0,25$ & $<0,001$ \\
\hline Bề dày thất trái tâm thu (mm) & $3,59 \pm 0,54$ & $3,11 \pm 0,26$ & $<0,001$ \\
\hline Bề dày VTL tâm trương (mm) & $3,01 \pm 0,37$ & $2,58 \pm 0,26$ & 0,001 \\
\hline Bề dày VLT tâm thu (mm) & $3,96 \pm 0,39$ & $3,58 \pm 0,38$ & 0,008 \\
\hline Chỉ số Tei thất phải & $0,42 \pm 0,03$ & $0,39 \pm 0,04$ & 0,059 \\
\hline Chỉ số Tei thất trái & $0,38 \pm 0,04$ & $0,37 \pm 0,04$ & 0,502 \\
\hline VTI động mạch chủ (cm/s) & $10,39 \pm 1,90$ & $7,56 \pm 0,30$ & $<0,001$ \\
\hline VTI động mạch phổi $(\mathrm{cm} / \mathrm{s})$ & $8,72 \pm 1,38$ & $6,66 \pm 0,19$ & $<0,001$ \\
\hline
\end{tabular}


Bề dày của các thành tim thai ở nhóm sản phụ có chỉ số kháng trở động mạch tử cung RI $>0,55$ lớn hơn một cách có ý nghĩa so với nhóm sản phụ có chỉ số $\mathrm{RI} \leq 0,55, \mathrm{p}<0,05$. Chỉ số VTI của tim thai nhi qua ĐMC, ĐMP ở nhóm sản phụ có chỉ số RI >0,55 cao hơn một cách có ý nghĩa với nhóm sản phụ có chỉ số $R I \leq 0,55$, $\mathrm{p}<0,001$.

Ớ các nghiên cứu về Doppler động mạch tử cung và tìm mối tương quan giữa RI với tình trạng bệnh lý TSG, đa số tác giả tìm ra ngưỡng giá trị RI tiên lượng tình trạng nặng của bệnh là $0,58^{9}$. Kết quả nghiên cứu của chúng tồi cho thấy điểm cắt RI là 0,55 có giá trị trong đánh giá sự thay đổi hình thái và chức năng tim thai. Thăm dò Doppler ĐMTC không những có giá trị tiên lượng tình trang thai mà còn có giá trị chẩn đoán nguyên nhân thai CPTTTC là về phía người mẹ mà cụ thể hơn là do nguyên nhân tuần hoàn của người mẹ. Kết luận này cũng tương tự như của Sudha Prasad (2017).

\section{KẾT LUÂ̂N}

1. Nghiên cứu cho thây chỉ số khối cơ thế (BMI), mức huyết áp tâm thu, huyết áp tâm trương và LDL-cholesterol của mẹ là những chỉ số lâm sàng có ảnh hưởng đến chức năng của tim thai toàn bộ, biểu hiện bằng chỉ số Tei thất phải và Tei thất trái $(p<0,05)$.

2. Chỉ số RI của động mạch tử cung tương quan thuận vói kích thuóc và bề dày thành tim thai $(p<0.05)$.

Ngưỡng RI > 0,55 cho thây sự khác biệt có ý nghĩa thống kê khi so sánh chỉ số tim ngực, bề dày thành tim, VTI ĐMC, ĐMP của tim thai có mẹ TSG và tim thai có mẹ khỏe mạnh với $p<0,05$.

\section{LờI CẢM ƠN}

Chúng tôi xin bày tỏ lòng biết ơn tới Lãnh đạo Bệnh viện Bạch Mai, khoa Phụ Sản, Viện Tim mạch Việt Nam và các phòng, ban của Bệnh viện Bạch Mai đã tạo điều kiện thuận lợi để hoàn thành nghiên cứu.

\section{TÀI LIÊU THAM KHẢO}

1. Ngộ Văn Tài. Một số yễu tố tiên lượng trong nhiểm độc thai nghén, Luận án tiến sỹ $Y$ học, Trường Đaai hoc Y Hà Nối. Published online 2001.

2. Ngô Văn Tài. Tiền sản giật và sản giật. In: Tiền Sản Giật và Sản Giật. 1st ed. Nhà xuất bản Y học; 2006:7-51.

3. Sibai B.M Ramadan K. "Pre-Eclamsia and Eclamsia", Sciarra.Obstet Gyneco, Vol .2, No.7, Pp.1-14.; 1995.

4. Comas M, Crispi F. Assessment of Fetal Cardiac Function Using Tissue Doppler Techniques. FDT. 2012;32(1-2):30-38. doi:10.1159/000335028

5. Dương Thị Bế. Nghiên cứu sự tác động của một số các yếu tố cận lâm sàng và lầm sàng trong nhiễm độc thai nghén taii Bệnh viên Phụ sản Trung ương trong 2 năm 2003-2004, luận văn tốt nghiệp bác sỹ chuyên khoa cấp II, Trường đại học Y Hả Nội.

6. Phạm Thị Mai Anh. Nghiên cứu thông số Doppler động mạch tử cung ở thai phụ tiền sản giật. Published online 2009.

7. Ayman Fouad Ahmed Sabry, Kumar S. Assessment of fetal cardiac function with maternal hypertension: Fetal echocardiography study. J Clin Exp Cardiolog. 2016;07(12). doi:10.4172/21559880.C1.063

8. Balli S, Kibar AE, Ece I, Oflaz MB, Yilmaz 0 . Assessment of fetal cardiac function in mild preeclampsia. Pediatr Cardiol. 2017;34(7):16741679. doi:10.1007/s00246-013-0702-8

9. Risk factors and clinical manifestations of pre-eclampsia - Ødegård - 2000 - BJOG: An International Journal of Obstetrics \&amp; Gynaecology - Wiley Online Library. Accessed November7, 2020. https:// obgyn.onlinelibrary. wiley. com/ doi/full/10.1111/j.1471-0528. 2000. tb11657.x

\section{MộT SỐ YẾU TỐ LIÊN QUAN ĐẾN THỜI GIAN CỬA - KIM Ở BÊNH NHÂN ĐộT QUỴ NHỒI MÁU NÃO CẤP ĐƯợC ĐIỀU TRI TIÊU HUYỂT KHỐI}

\section{TÓM TẮT}

\footnotetext{
${ }^{1}$ Trường Đại học Y Hà Nội,

2Bệnh viện Đại học Y Hà Nội,

${ }^{3}$ Bênh viên Bach Mai

Chiu trách nhiệm chính: Hoàng Bùi Hải

Email: hoangbuihai@hmu.edu.vn

Ngày nhận bài: 15.10 .2020

Ngày phản biên khoa họ: 20.11.2020

Ngày duyệt bài: 3.12.2020
}

\section{Đặng Trung Anh ${ }^{1}$, Hoàng Bùi Hải ${ }^{1,2}$, Mai Duy Tôn ${ }^{3}$}

Nghiên cứu nhằm mô tả một số yếu tố liên quan đến thời gian cửa - kim (DTNं), là thời gian từ khi bệnh nhân nhập viện đến khi bệnh nhân được dùng thuốc tiêu huyết khối ở các bệnh nhân đột quy nhồi máu não cấp. Đây là phương pháp hồi cứu mô tả tại bệnh viện Đại học Y Hà Nội và Bạch Mai trên 124 bệnh nhân đã được chẩn đoán nhồi máu não cấp và được điều trị tiêu huyết khối. Kết quả cho thây có phim chụp so não trước khi đến viên, liên hê trước với bệnh viện, vào viện trong giờ hành chính và thời gian nhập viện - thăm khám (DTE) ngắn là các yếu tố độc lập liên quan đến thời gian cửa - kim < 60 phút. Từ 